\title{
Selective ablation of thin films in latest generation CIGS solar cells with picosecond pulses
}

\author{
Andreas Burn ${ }^{1 \mathrm{a}}$, Valerio Romano ${ }^{\mathrm{a}}$, Martin Muralt ${ }^{\mathrm{a}}$, Reiner Witte ${ }^{\mathrm{b}}$, Bruno Frei $^{\mathrm{b}}$, Stephan Bücheler ${ }^{\mathrm{c}}$, \\ Shiro Nishiwaki ${ }^{\mathrm{C}}$ \\ ${ }^{a}$ Bern University of Applied Sciences, Pestalozzistrasse 20, CH-3400 Burgdorf, +41 34426 4141; \\ ${ }^{\mathrm{b}}$ Solneva SA, Alte Lyssstrasse 2, CH-3270 Aarberg, +41 31588 2500; \\ ${ }^{c}$ Laboratory for Thin Films and Photovoltaics, EMPA, Swiss Federal Laboratories for Materials \\ Science and Technology, Überlandstrasse 129, CH-8600 Dübendorf, +41 448235511
}

\begin{abstract}
Recent developments in $\mathrm{Cu}(\mathrm{In}, \mathrm{Ga}) \mathrm{Se}_{2}$ (CIGS) thin film photovoltaics enabled the manufacturers to produce highly efficient solar modules. Nevertheless, the production process still lacks a competitive process for module patterning. Today, the industry standard for the serial interconnection of cells is still based on mechanical scribing for the P2 and $P 3$ process. A reduction of the non-productive "dead zone" between the P1 and P3 scribes is crucial for further increasing module efficiency. Compact and affordable picosecond pulsed laser sources are promising tools towards alllaser scribing of CIGS solar modules. We conducted an extensive parameter study comprising picosecond laser sources from 355 to $1064 \mathrm{~nm}$ wavelength and 10 to $50 \mathrm{ps}$ pulse duration. Scribing results were analyzed by laser scanning microscope, scanning electron microscope and energy dispersive X-ray spectroscopy. We developed stable and reliable processes for the P1,P2 and P3 scribe. The best parameter sets were then used for the production of functional minimodules. For comparison, the same was done for a selection of nanosecond pulsed lasers. Standardized analysis of the modules has shown superior electrical performance of the interconnections and confirmed the feasibility of a dead zone width of less than $200 \mu \mathrm{m}$ on an entire mini module.
\end{abstract}

Keywords: CIGS thin film, picosecond laser, selective ablation, solar cell, laser scribing, patterning, low dead zone, high efficiency

\section{INTRODUCTION}

Today, the terrestrial Photovoltaic (PV) market is dominated by crystalline silicon wafer technology. However, thanks to extensive research and development in the field, thin-film alternative techniques are evolving at high pace and rapidly gaining ground. Among the thin-film absorber materials $\mathrm{Cu}(\mathrm{In}, \mathrm{Ga}) \mathrm{Se}_{2}$ (CIGS) systems boast highest-in-class efficiency, stable performance, low toxicity and relatively low production costs. High efficiency can be maintained in a full PV panel by subdividing the cell area into small segments that are connected in series. These connections ("monolithic interconnects" as they are often called) consist of three scribing processes P1, P2 and P3 where the number stands for the coating process step after which they are applied. Figure 1 shows possible connection schemes and scribe configurations. For a typical panel size of $1200 \mathrm{~mm} \times 600 \mathrm{~mm}$ about 100 interconnections have to be created. It becomes obvious that the width of the connection zone and the electrical quality of the connection are critical parameters for the overall module efficiency. Today, the industry standard P2 and P3 process for patterning CIGS thin film solar modules is still mechanical scribing. This process is established and well known but it has major disadvantages. The mechanical scribing head needs regular maintenance due to wear of the needles and this means additional costs and downtime of the machine. Further, the process itself suffers from non-predictable irregular outbreaks at the scribe borders - the chipping effect (see[1] and the references therein). Substantial scribe-to-scribe distances are therefore necessary to prevent module failure due to electrical shorts at the interconnections. At present, the typical dead zone (non-productive zone consisting of the three scribes P1-P3) measures about $500 \mu \mathrm{m}$ across. The major part of this dead zone acts as a safety margin; therefore it is highly desirable to reduce this non-productive area by developing more reliable and predictable scribing processes.

${ }^{1}$ andreas.burn@bfh.ch; phone: +41 34426 4246; www.ti.bfh.ch/alps

$824318 \cdot$ ? 2012 SPIE · CCC code: 0277-786X/12/\$18 - doi: 10.1117/12.906919 
a)
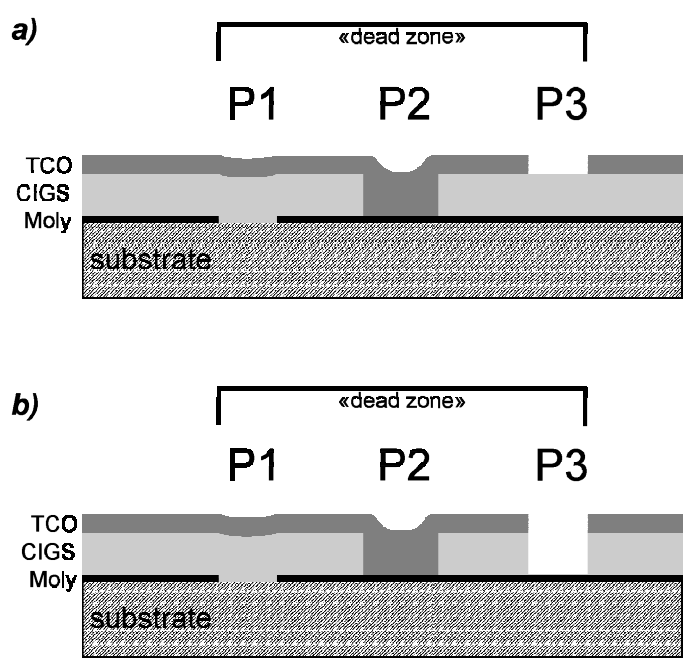

Figure 1 Cross section at the interconnection illustrating the arrangement of the different scribes. P1 stands for a scribe in the molybdenum layer, P2 removes the CIGS film down to the molybdenum (Mo) layer and the P3 scribe removes either only the transparent conducting oxide (TCO) film as shown in graphic a) or all layers down to the Mo-film, graphic b). The entire interconnection zone comprising the three scribes is called "dead zone".

A realistic goal for an industrial process is a reduction of the dead zone width by at least 50 percent. Nowadays, the lowmaintenance tool of choice is the pulsed laser which also became affordable with the advent of efficient and highly integrated fiber laser sources.

In the present study we evaluated several picosecond pulsed laser sources for their suitability for each of the three scribing processes. We tried to identify large and robust scribing process windows in a large parameter field. The suitability of a process was rated according to the overall scribe quality, reproducibility and size of the process window. The best rated processes for each of the P1-3 scribes have been selected for the production of a functional mini module. For comparison, the same selection has been made for short nanosecond pulsed laser sources.

\section{EXPERIMENTAL}

\subsection{Samples}

Sample coatings were grown on $50 \times 50 \times 1 \mathrm{~mm}^{3}$ float glass substrates at the Laboratory for Thin Films and Photovoltaics, EMPA, Dübendorf, Switzerland. Molybdenum was grown by DC sputtering onto the glass substrate as electrical back contact. The $\mathrm{Cu}(\mathrm{In}, \mathrm{Ga}) \mathrm{Se}_{2}$ absorber material was deposited by co-evaporation of the elements in a modified 3-stage process followed by a thin CdS buffer layer grown by chemical bath deposition and an i-ZnO/ZnO:Al bilayer grown by RF sputtering[2].

\subsection{Laser sources and experimental setup}

As a general frame we set the following basic requirements to our laser sources:

- $\quad$ beam quality, $\mathrm{M}^{2}<1.5$

- near Gaussian beam profile

Further, we selected laser sources according to the already published numbers[3-6] for the minimum necessary pulse energy for ablation. Table 1 shows an overview on the picosecond laser sources used in this study. 
The optical beam path was kept as simple as possible, so we used only a focusing lens and no diaphragm or beam shaping optics. The focusing optics used were f-theta lenses with focus lengths of $100 \mathrm{~mm}$ and $160 \mathrm{~mm}$ for the ps scribes and a $\mathrm{f}=50 \mathrm{~mm}$ plano-convex lens with appropriate coating for the ns experiments. The focusing optics produced waist diameters between $10 \mu \mathrm{m}$ and $34 \mu \mathrm{m}$ (depending on the wavelength and focus length) with a Gaussian intensity profile. The nature of the task does suggest that a flatter beam profile would possibly produce cleaner borders than a Gaussian. However, we wanted to keep the system as simple and versatile as possible and invested our experimental time on finding possible processes at all in a vast parameter field; we spared the tweaking for later. The ps scribes were all made using a galvanometric scanner head. For the ns lasers we used either a high precision X-Y linear motor motion system or a scanner.

Table 1 Picosecond laser sources used in this study.

\begin{tabular}{|c|c|c|c|}
\hline \multirow{2}{*}{$\begin{array}{l}\text { pulse } \\
\text { length }\end{array}$} & \multicolumn{3}{|c|}{ wavelength } \\
\hline & $355 \mathrm{~nm}$ & $532 \mathrm{~nm}$ & $1064 \mathrm{~nm}$ \\
\hline $10 \mathrm{ps}$ & $\sqrt{ }$ & $\checkmark$ & $\checkmark$ \\
\hline $30 \mathrm{ps}$ & $\checkmark$ & $\checkmark$ & $\checkmark$ \\
\hline $50 \mathrm{ps}$ & $\checkmark$ & $\checkmark$ & $\checkmark$ \\
\hline
\end{tabular}

We used a master oscillator power amplifier (MOPA) source where the pulse length of the oscillator can be modified by introducing an etalon. This laser system is further equipped with a second and third harmonic stage. By using the MOPA we could guarantee a high beam quality and comparable beam parameters throughout the measurement series. Such a system is of course too expensive for the use on an industrial machine, but once the parameters have been chosen, it tells us where we have to get with a potential fiber laser system. In order to put our results in relation to the results that can be obtained with nanosecond ablation processes, we made another series of measurements using the following laser parameters (wavelength, pulse duration): ( $\lambda=532 \mathrm{~nm}, \tau=1.5 \mathrm{~ns}) ;(\lambda=1064 \mathrm{~nm}, \tau=25 \mathrm{~ns}$ and $\tau=10 \mathrm{~ns}) ;(\lambda=1550 \mathrm{~nm}, \tau=3.2$ ns).

\subsection{P1 scribe}

At the production stage of the P1 process, a glass substrate with a molybdenum (Mo) coating on one side has to be patterned. The 500 to $750 \mathrm{~nm}$ thick Mo layer must be divided into electrically isolated lanes which are the base for the later single PV cells. This first step offers some freedom in the process design because of the transparent substrate. The ablation of the Mo layer can be done either from the layer side as a top-down ablation or from the backside through the glass substrate. In the latter case, the Mo layer is locally blast off by rapidly expanding gases created by the absorbed laser pulse at the interface between glass and Mo film.

The primary goal of the $\mathrm{P} 1$ process is electrical isolation, we therefore require a resistance $>20 \mathrm{M} \Omega$ on a scribe length of $1 \mathrm{~cm}$. Geometrically, a high quality P1 scribe is characterized by a clean bottom of the trench, a sharp rupture at the borders, a small heat-affected zone (HAZ) and minimal burr formation (as burrs could compromise the subsequent coating processes).

We compared layer-side and substrate-side ablation for all laser parameters and the result was clear: the ablation from the substrate side produced much better results. As the micrograph in Figure 2 shows for the case of $30 \mathrm{ps}$ pulse length at $532 \mathrm{~nm}$ and varying overlap, substrate-side ablation produces cleaner borders, smaller HAZs and cleaner trench bottoms. The ablation from the layer side suffers mainly from partial melting of the Mo even at the shortest pulse length of $10 \mathrm{ps.}$ The pulse energy or the overlap needed to create an electrically isolating scribe is much higher than for the backside ablation. High energy pulses are expensive, difficult to transport in optical fibers and they often damage the substrate. Ablation at high overlap ratios created relatively nice trenches but a large HAZ. Best results for layer-side ablation were obtained at $355 \mathrm{~nm}$ with $10 \mathrm{ps}$ pulses but as for all layer-side P1 processes, the process window is small and depends strongly on the sample. 

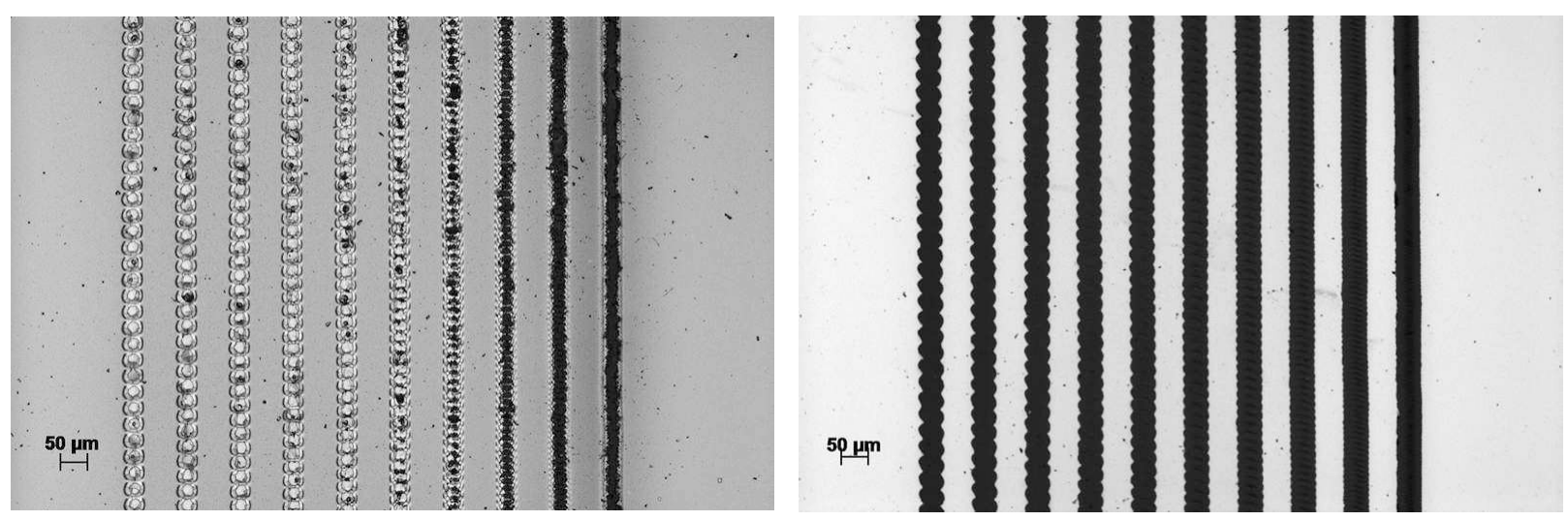

Figure 2 Micrograph of a P1 scribe on a $\sim 0.6 \mu \mathrm{m}$ Mo layer. Laser parameters: $1064 \mathrm{~nm}, 30 \mathrm{ps}, 50 \mathrm{kHz}, 40 \mu \mathrm{J}$ (left) and $4 \mu \mathrm{J}$ (right), overlap 10-80\%. Comparison between layer-side ablation (left) and backside ablation (right).

For a high quality P1 process it seems that there is no way around backside processing of the Mo-layer. One disadvantage of this backside processing is its high sensitivity to impurities in the bulk of the substrate and dirt on the surface which can locally interrupt the scribing process. However, with today's high quality float glass and industrial cleanroom conditions this should not be a big problem. A broad range of working parameters can be found easily for all wavelengths and (picosecond) pulse durations. The lift-off process (Figure 3 and Figure 4) works similarly well for all wavelengths and pulse widths. Differences are found in details: working with 10 ps pulses increases the risk of substrate ablation at the Mo-glass interface in comparison to 50 ps pulses; and working at $355 \mathrm{~nm}$ more easily damages the substrate due to the lower transmission in this spectral region. An interesting phenomenon - the formation of molten molybdenum droplets in the scribe center - was observed for green light at $50 \mathrm{ps}$ only (see Figure 5. In this situation, the laser beam perhaps works as optical tweezers, but we did not further investigate that. From the good overall performance, process stability and ease of handling we decided to use $1064 \mathrm{~nm}, 50 \mathrm{ps}$ for the P1 scribe.

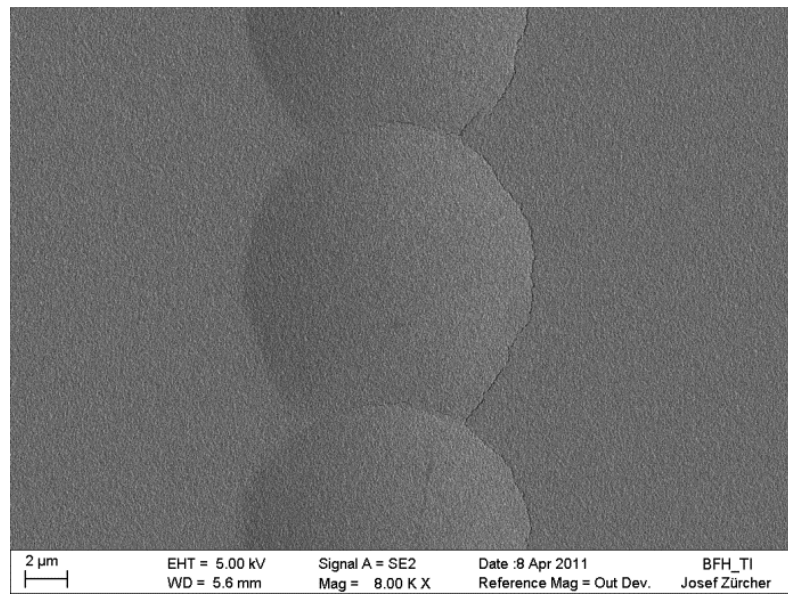

Figure 3 Electron micrograph illustrating the mechanics of the backside P1 process (at pulse energy below the threshold). Rapidly expanding gases separate the Mo layer from the glass substrate in the region of absorption. A circular crack is created around the target spot region.

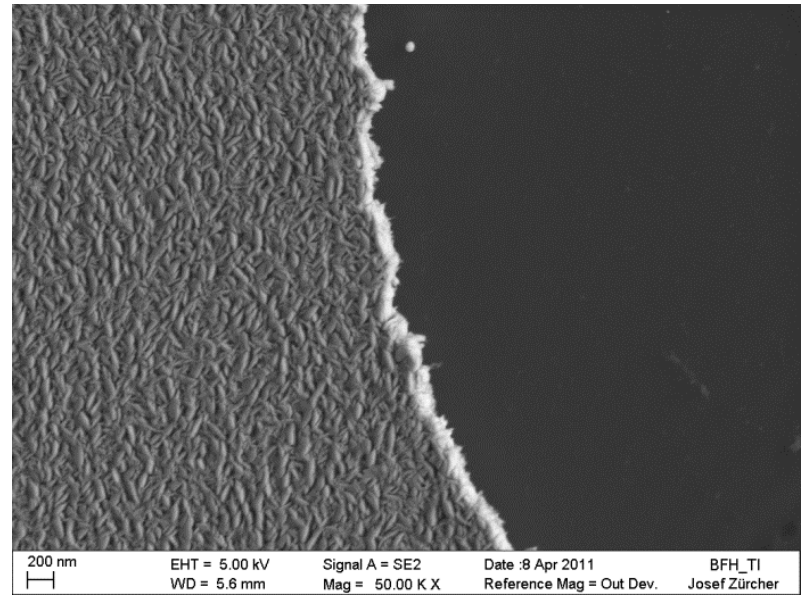

Figure 4 When the pulse energy is high enough, the Mo film is removed completely and a sharp edge is exposed. High magnification electron micrograph of a P1 scribe (532 nm, $10 \mathrm{ps})$ showing the welldefined scribe border, clear substrate and no melting of the Mo-film. 


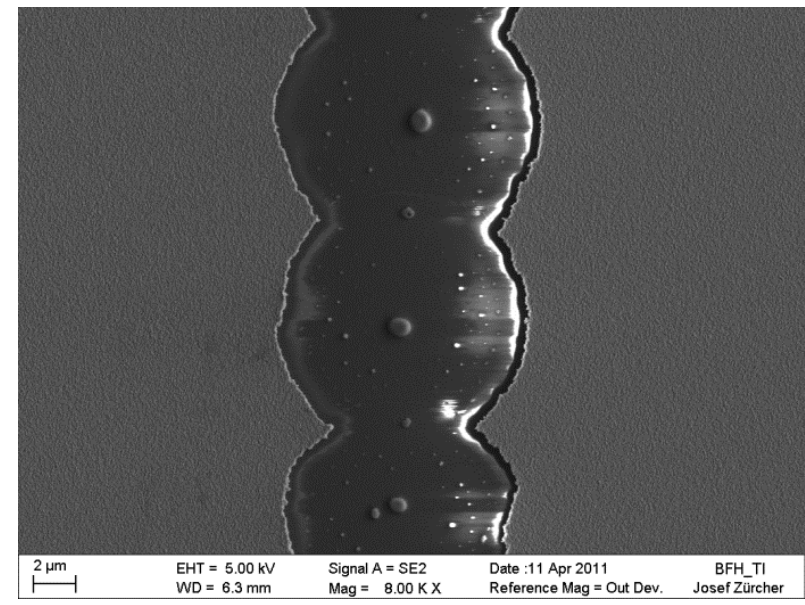

Figure 5 Electron micrograph of a P1 scribe made at 532 $\mathrm{nm}, 50 \mathrm{ps}$; formation of molten droplets in the center of the trench.
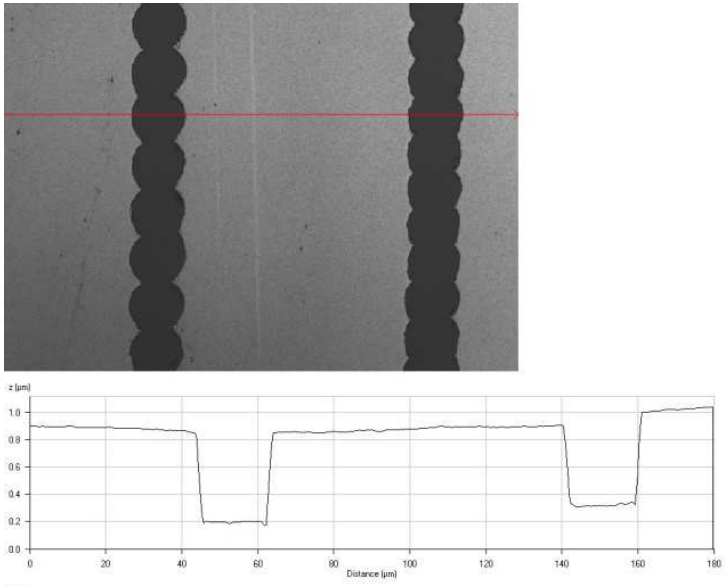

Figure 6 Laser scanning microscopic (LSM) image of a P1 scribe made at $1064 \mathrm{~nm}, 30 \mathrm{ps}$. The height profile illustrates the sharp step at the scribe border.

As mentioned, we also made some experiments with nanosecond laser systems for comparison. As in the case of the picosecond process the Mo-layer has to be removed from the substrate side. Figure 7 shows a typical example of such a scribe. The most common problems are also illustrated by this electron micrograph: nanosecond laser scribes (at least in our case) were more likely to have cracks in the Mo film along the scribe as shown in Figure 8. Some molten material is also regularly found along the scribe edge which tends to form small burrs. By far the most important problem is flaking which was commonly observed for ns processes. A part of the border region of the film is separated from the substrate and remains as more or less attached flakes at the scribe border. Such flakes can cause problems during the consecutive coating processes and may also compromise mechanical stability and durability of the electrical interconnection. These results were obtained on our standard $\sim 0.6 \mu \mathrm{m}$ Mo coated samples. There are indications, however, that samples of other manufacturers and/or thinner Mo films can be patterned using ns laser pulses without these adverse effects (see [7] for example).

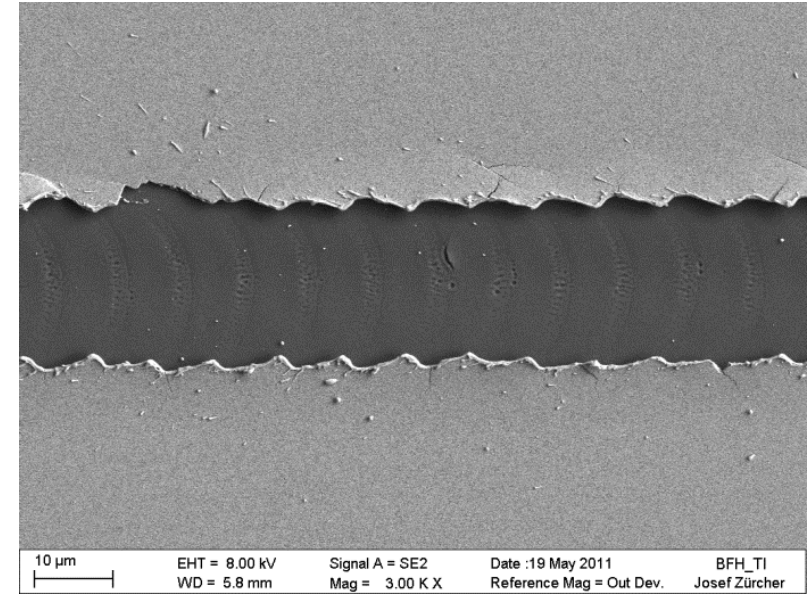

Figure 7 Electron micrograph of a P1 scribe made with a nanosecond laser $(\lambda=1550 \mathrm{~nm}, \tau=3.2 \mathrm{~ns})$

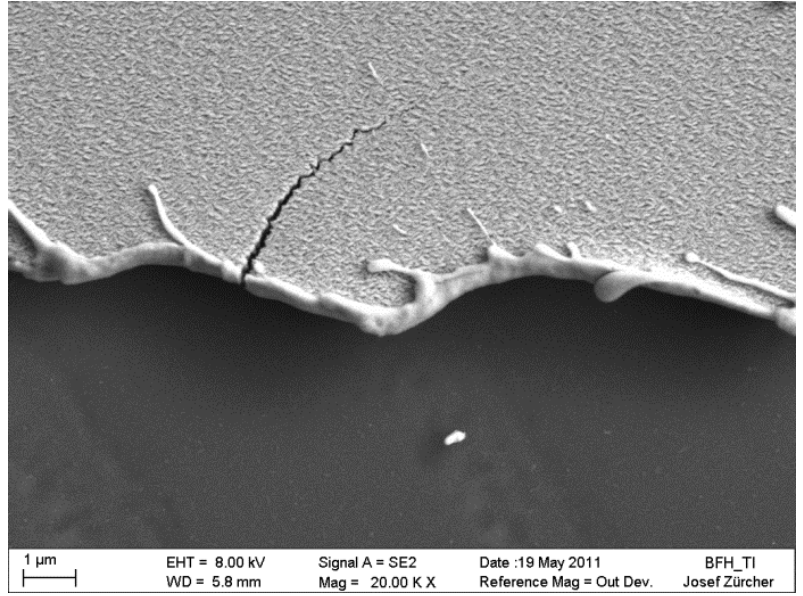

Figure 8 Detail of the scribe border region in Figure 7. Cracks and flaking as well as melting are often observed for ns $\mathrm{P} 1$ processes at all wavelengths. 


\subsection{P2 scribe}

During the $\mathrm{P} 2$ process step, the $\mathrm{Cu}(\mathrm{In}, \mathrm{Ga}) \mathrm{Se}_{2}$ or CIGS absorber layer has to be removed down to the Mo film as shown in Figure 9. A good P2 scribe removes the CIGS completely from the Mo-layer without damaging it. This is important as it facilitates good adhesion of the TCO layer which results in a mechanically stable, low resistance electrical contact. The CIGS absorber is a particularly difficult material to be laser-ablated. One reason is the rapid melting of CIGS, as a consequence there is no such thing as "cold ablation" in the pulse length range above 10 ps. Even 10 ps pulses always produce melt and once the material is molten, it is not easy to remove it from the trench bottom.

\section{P1 P2 P3}
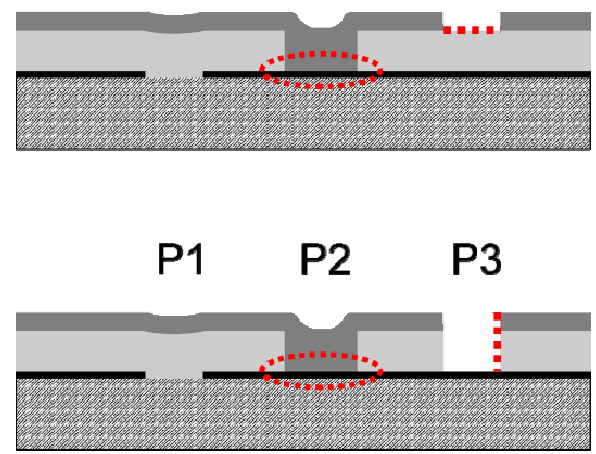

Figure 9 Key zones for the P2 and P3 processes: electrical contacting zone for the $\mathrm{P} 2$ and possible horizontal and vertical shorts (dashed line) when CIGS material is molten in the P3 process.

If it is not possible to ablate CIGS without leaving molten borders, the question arises whether this re-molten CIGS has adverse effects on the functionality of the PV module. According to[1,8], re-molten and solidified CIGS acts basically as an electrical conductor. Since our goal is to create a connection between TCO and Mo back-contact, we do not mind if there are conducting walls on each side of the scribe as long as the conducting material is contained in a small zone around the scribe and does not interfere with the isolating P1 scribe. Experimental results have shown that CIGS laser ablation works most reliably at $532 \mathrm{~nm}$; we achieved results such as Figure 10 and Figure 11, which were encouraging.

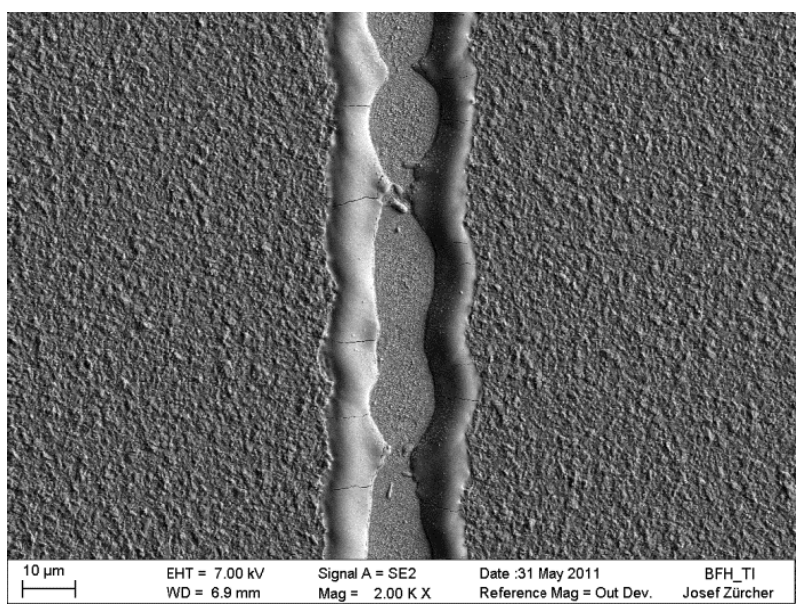

Figure 10 Suboptimal scribe (Mo undamaged, but exposed zone too small and remaining CIGS in the trench).

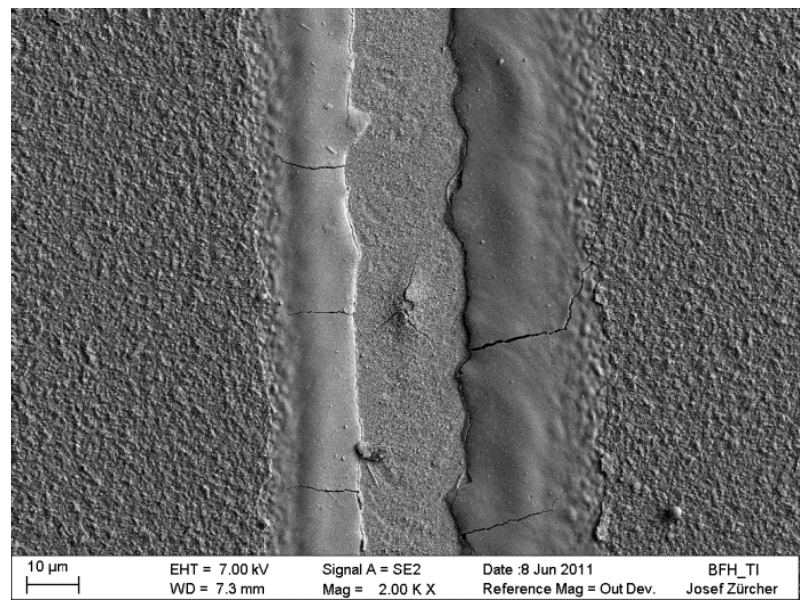

Figure 11 Suboptimal scribe (trench wide enough and clean, but Mo back-contact is damaged, large HAZ and many long cracks) 
For the further process development we defined the following quality criteria:

- Mo back-contact integrity (fully exposed, clean, no cracks, no lifting)

- relation between width of the exposed Mo-film and width of the molten CIGS zone

- $\quad$ height and profile of the burr (small is better than large, smooth is better than sharp-edged)

- cracks and bubbles in the molten CIGS (as little cracks/bubbles as possible)

These quality criteria were used for fine-tuning the process. We rated the scribes made at pulse durations of $10 \mathrm{ps,} 30 \mathrm{ps}$ and $50 \mathrm{ps}$, with varying pulse energies and overlap. It became obvious that the P2 process window is considerably smaller than in the case of the P1 scribe. However, the yield of the parameter study was a set of P2 parameters for creating scribes as shown in Figure 12.
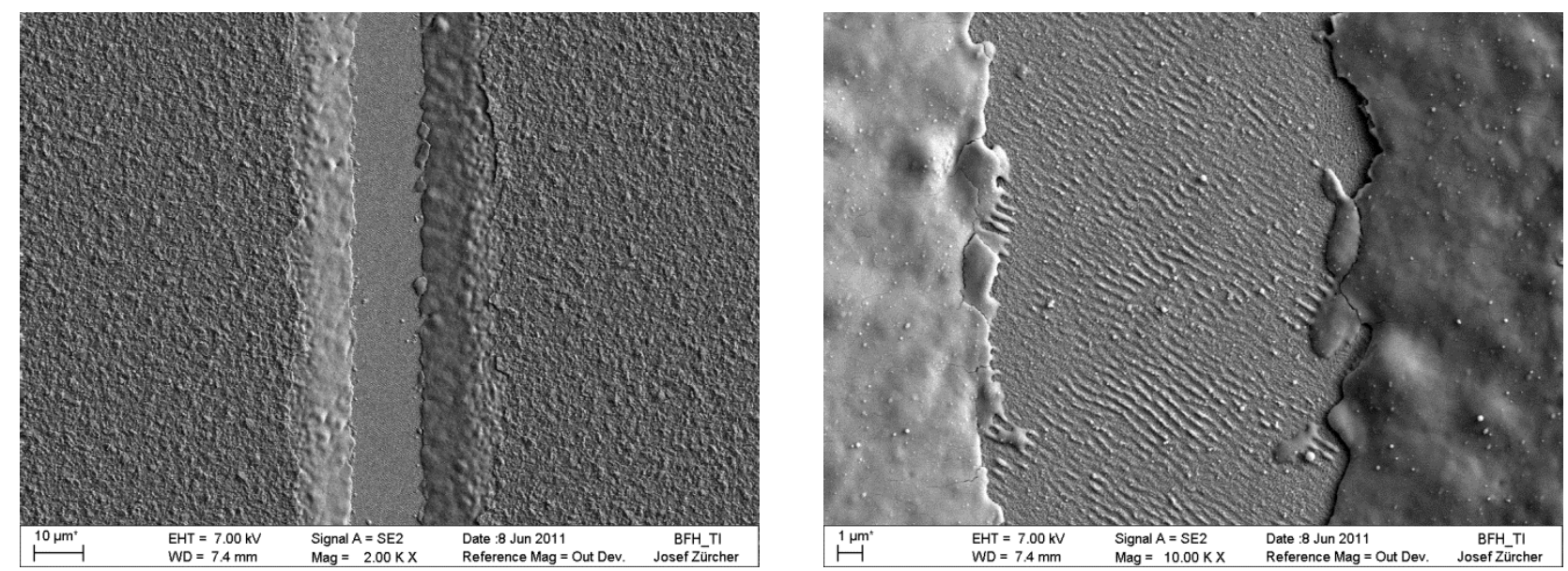

Figure 12 Optimized P2 scribe featuring a sufficiently large zone of exposed Mo for good contact. The magnification on the right shows that the Mo film is not damaged.

It remains to be said that this $\mathrm{P} 2$ process produces wedged borders. While this trench profile facilitates a regular conformal coating with the TCO film it certainly consumes a bit more space than a sharp edge would. The large zone of re-molten CIGS is mainly a result of the Gaussian intensity distribution in the focal spot. As shown in [9] the shaping of the Gaussian beam into a top hat profile (in the focal plane) by a diffractive element could significantly reduce the extension of the zone of re-molten CIGS while maintaining the main characteristics of the scribe.

There was no similar top-down process possible for nanosecond pulses as they produce excessive heat when they are absorbed in the CIGS. Once the CIGS is molten it is basically boiled away, this leaves bubbles in the CIGS and a large HAZ. One possible solution is an induced ablation process with the Mo acting as an absorber at a wavelength where CIGS transmission is high enough. A good candidate is $1550 \mathrm{~nm}$ but we found out that one of the upper buffer or window layers absorbs the energy and creates heat. For some CIGS absorbers the transmission at $1064 \mathrm{~nm}$ is high enough for an induced ablation process which creates practically no melt and cleanly fractured borders (see Figure 13). The process worked well for single pulses but failed for continuous scribes. This is a very interesting result which we will further investigate. Since this process was discovered late in the study and for the moment it wasn't possible to make a continuous scribe we decided to resort to the picosecond P2 process also for the nanosecond functional sample. 


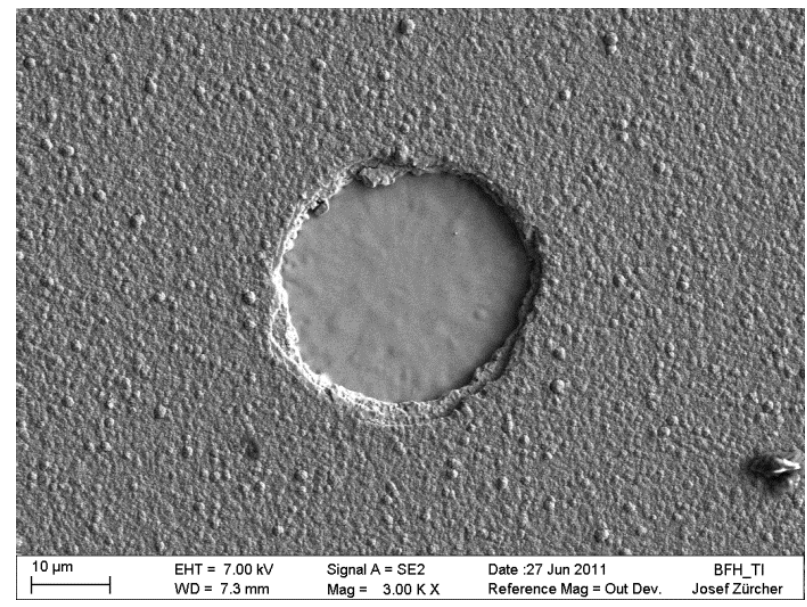

Figure 13 Induced ablation process. Effect of a single pulse $1064 \mathrm{~nm}, \tau=10 \mathrm{~ns}$ on a Mo/CIGS/ZnO stack.

\subsection{P3 scribe}

The third scribing process electrically isolates the individual PV cells by removing the TCO front contact layer locally. This process step completes the serial interconnection of the cells. As shown in Figure 1, there are two possibilities to achieve that - by removing the TCO only or by removing all layers down to the Mo back-contact. Both strategies can be equally successful. The main problem is once again CIGS melting, but - other than in the P2 process - we cannot tolerate electrically conducting zones in the CIGS as this would directly affect module performance. Critical regions for the P3 process are marked in Figure 9: when only the TCO is removed, horizontal shorts can be created when the CIGS is molten such as in Figure 14; vertical shorts can be created when CIGS and TCO are removed such as in Figure 15.

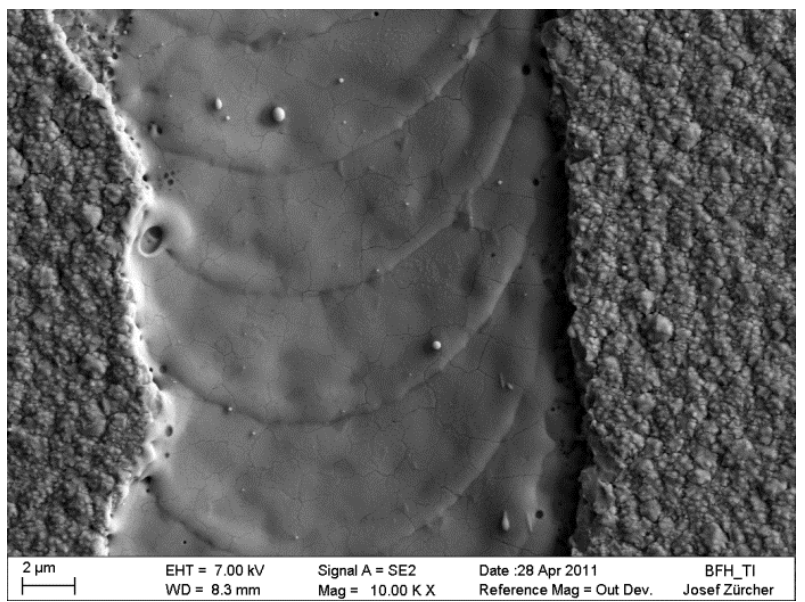

Figure 14 Unsuccessful P3 scribe, removal of the TCO only. Molten CIGS forms horizontal short between neighboring cells.

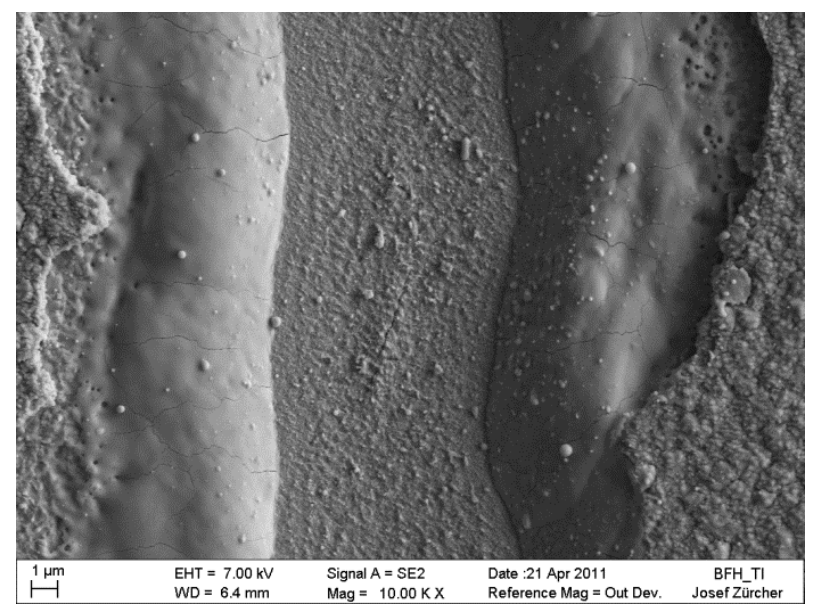

Figure 15 Unsuccessful P3 scribe, removal of CIGS and TCO. Molten CIGS sidewalls form vertical shorts between front and back-contact.

On our samples the TCO used as front contact was (ZnO:Al). This material has by design a high transmission in the near infrared (NIR) to the visible spectral range but the absorption is high in the UV. Direct ablation of the (ZnO:Al) layer has been reported using picosecond laser sources at $266 \mathrm{~nm}$ and $355 \mathrm{~nm}[3,10]$ or using a femtosecond laser system[11]. Both strategies could work for our samples but the laser sources used have one common drawback: the light cannot be transported efficiently in an optical fiber. Our experiments at $355 \mathrm{~nm}$ have shown that attacking the TCO layer directly 
often produces residues of molten $\mathrm{ZnO}: \mathrm{Al}$ which remain in the trench or $\mathrm{Al}$ ions diffusing in the CIGS. Additionally, there is still 38 percent of the total pulse energy transmitted ${ }^{2}$ to the CIGS at $355 \mathrm{~nm}$ which causes non-acceptable melt.

Fiber deliverability is important for the transfer of the process to an industrial machine, so we were encouraged to find another process which uses laser sources already available in this study. If a laser wavelength of $532 \mathrm{~nm}$ or $1064 \mathrm{~nm}$ is to be used with picosecond pulses, the process we are looking for must be an induced ablation process powered by the absorption at the CIGS surface. Since the penetration depth in the CIGS is considerably higher in the NIR than in the visible, we decided to use $532 \mathrm{~nm}$ for this process step. We found process windows for $10 \mathrm{ps,}, 30 \mathrm{ps}$ and $50 \mathrm{ps}$ at 10 to 40 percent overlap (in relation to the beam waist diameter $2 \omega_{0}$ ). The shorter pulses often left cracks in the neighboring TCO but produced almost no melt of the CIGS. A smoother process could be achieved using longer pulses which lead to a very clean ablation with some melting in the trench. We chose the middle ground and fine-tuned the process for $30 \mathrm{ps}$ pulses. An example of a scribe made with these laser parameters is shown in Figure 16.

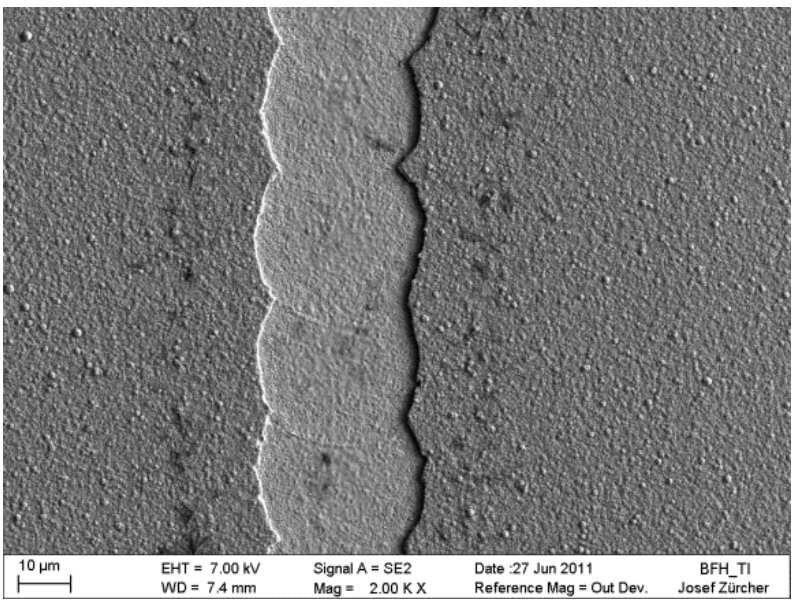

Figure 16 Electron micrograph of a P3 scribe made at $532 \mathrm{~nm}$ with $30 \mathrm{ps}$ pulse length. Some debris remained on the surface due to the lack of a suction system.

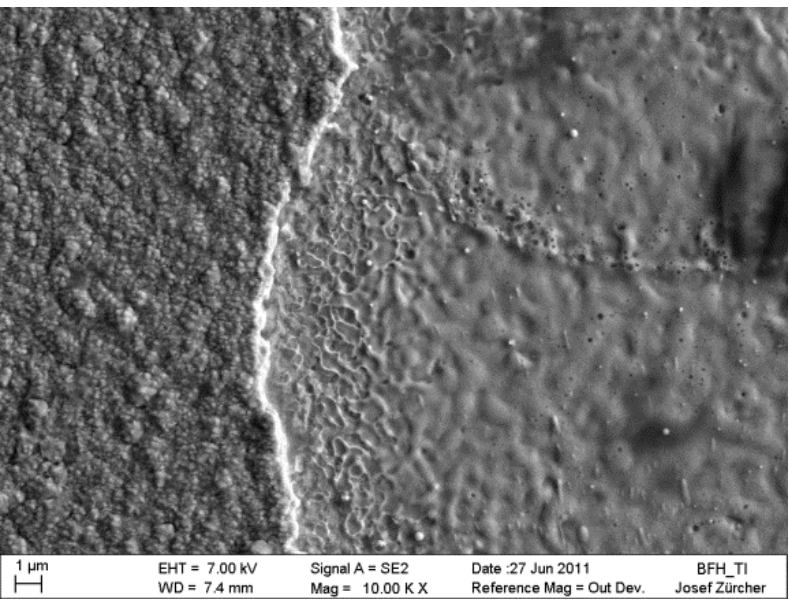

Figure 17 Magnified EM image of the scribe border. The TCO layer is cleanly removed and no cracks are visible. Some melt is produced in the trench center as a result of the Gaussian beam intensity profile.

We have also found a process using a nanosecond pulsed laser. The best results were achieved at $1.5 \mathrm{~ns}$ at $532 \mathrm{~nm}$ with an overlap of 10 to $20 \%$. Naturally, more material is molten in a nanosecond process but the results obtained were nonetheless very encouraging as the best achievable results are close to the ones in a picosecond process as Figure 18 shows. Whether the molten CIGS in the trench already affects the electrical isolation has to be carefully investigated for the films of a specific manufacturer.

\footnotetext{
${ }^{2}$ Measured optical properties of the ZnO layer yielded the following absorption properties: 89\%@266 nm, 38\%@355 nm and $<1 \%$ for $532 \mathrm{~nm}, 1064 \mathrm{~nm}$ and $1550 \mathrm{~nm}$.
} 


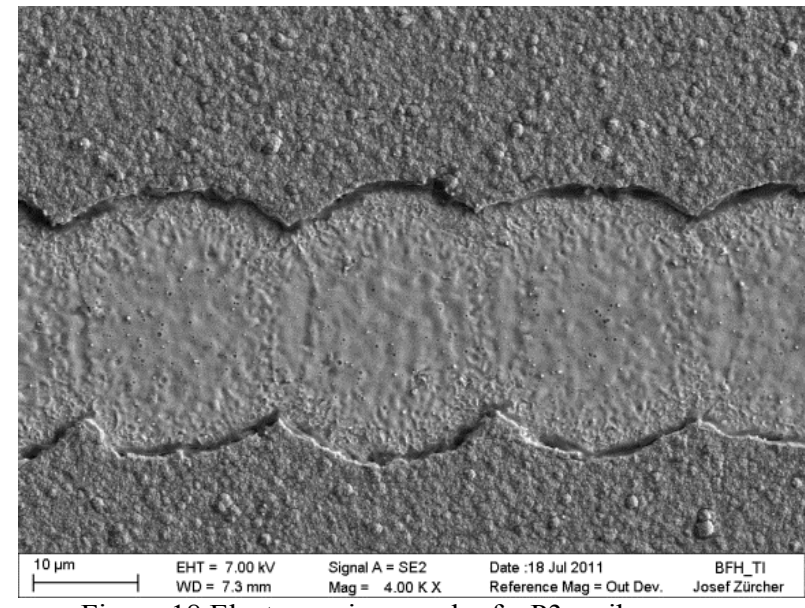

Figure 18 Electron micrograph of a P3 scribe made at $532 \mathrm{~nm}$ with $1.5 \mathrm{~ns}$ pulse length.

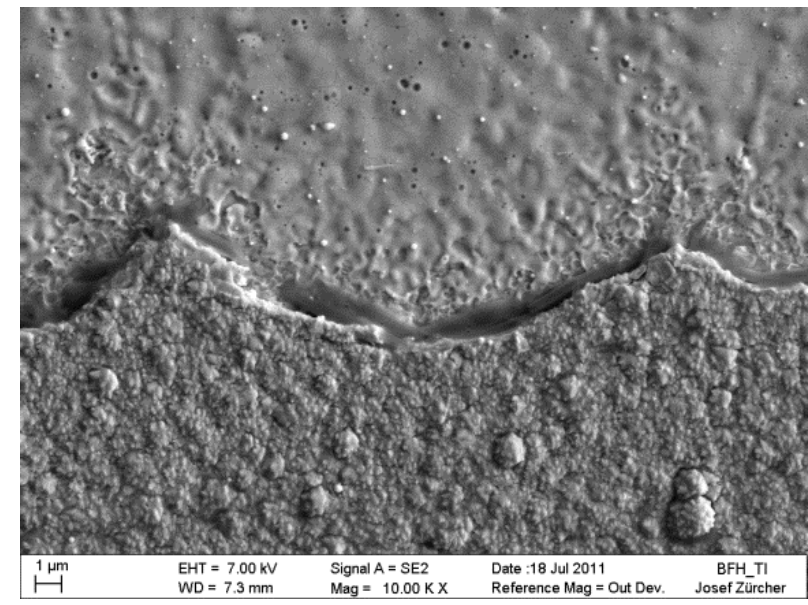

Figure 19 Detail of the scribe border. The TCO layer is cleanly removed but the molten region extends almost to the scribe border.

\subsection{Isolation scribe}

In order to isolate the active PV module surface from possible production defects at the substrate borders, an isolation scribe is usually made along the edge of the substrate. Since we are heading towards all-laser scribing we wanted to find a laser-based alternative to the mechanical standard. Even though this scribe is not part of the cell interconnection, it is as important as the P1-P3 scribes because it has the potential of ruining an otherwise perfectly made PV module. This is especially true for a laser process as this has the potential of melting the CIGS along the scribe which then causes vertical shorts between front and back-contact. The goal is therefore not to melt the CIGS which is possible when a modified P1 process is used. All laser sources used for the P1 backside ablation can also potentially be used for the isolation scribe. Substrate damage threshold sets some constraints, however, on the peak intensity of the pulses. Since the energies needed for clean removal of the complete layer stack are considerably higher than in the P1 process, the longer pulses better suit the task as they cause less damage to the substrate. A disadvantage of this process is the fact that the substrate has to be flipped over again at the end of the production cycle.

An alternative strategy is shown in Figure 20. Here, we integrated the P1 and P3 scribe into the isolation scribe at their specific stage in the production process. At the end of P3 scribing an additional scribe can optionally be made which removes the complete layer stack down to the substrate. This last scribe can also be of lower quality (i.e. it can be made also from the layer side or with longer pulses) because potential vertical shorts due to molten CIGS are electrically isolated from the front and back-contact.

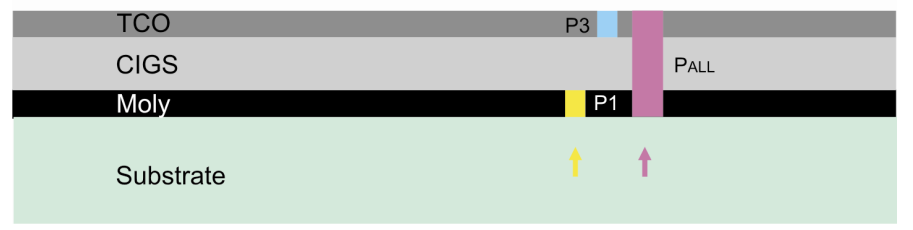

Figure 20 Isolation scribe strategy with integration of the $\mathrm{P} 1$ and $\mathrm{P} 3$ scribes at their process stage and the optional $\mathrm{P}_{\mathrm{ALL}}$ process which removes all three layers. The illustration shows the optimum scribe arrangement for process stability. 


\section{FUNCTIONAL MINI MODULE}

Functional 8-cell mini modules with substrate dimensions $50 \times 50 \mathrm{~mm}^{2}$ were produced at the end of the study in order to test process stability of the P1-P3 scribes under production-like conditions. The mini-module substrates were cut and Mo-coated at the EMPA Laboratory for Thin Films and Photovoltaics in Dübendorf, Switzerland. Subsequently, the samples were laser-patterned at Bern University of Applied Science and sent back for the next thin film deposition process step. They went back and forth until finished. After completion, the samples were tested and microscopically and electrically analyzed.

We produced a total of four mini-modules. On three of them we varied the distance between the scribes in order to check out the limits of dead-zone reduction. On one module nanosecond pulses were used for the P1 and P3 process steps. The isolation scribe was planned according to Figure 20 but it had to be completed by mechanical means because scratches and coating residues on the substrate backside interfered with the backside ablation processes. These, however, were problems specific to the laboratory conditions and excessive manipulation during alignment of the samples.

\subsection{Scribing parameter selection}

The laser parameters selected for patterning the functional mini-modules are presented in Table 2. All P1 scribes were made from the substrate side. For P2 and P3 scribes, the laser illuminated the layer-side of the substrate. For P1 and P3 the best nanosecond process was used on one mini-module for comparison. Picosecond patterning was done by means of a galvanometric scanner head controlled by a PC. All nanosecond scribes were made on a high precision X-Y motion system where the sample was moved across the focus of the laser beam.

Table 2 Laser parameters selected for the mini-module production

\begin{tabular}{|c|c|c|c|}
\cline { 2 - 4 } \multicolumn{1}{c|}{} & $\lambda / \mathrm{nm}$ & $\Delta \tau / \mathrm{ps}$ & $\mathrm{w}_{0} / \mu \mathrm{m}$ \\
\hline P1 (ps) & 1064 & 50 & 17 \\
\hline P1 (ns) & 1550 & 3200 & 21 \\
\hline \multicolumn{4}{|c}{} \\
\hline P2 & 532 & 30 & 20 \\
\hline P3 (ps) & 532 & 30 & 20 \\
\hline P3 (ns) & 532 & 1500 & 15 \\
\hline
\end{tabular}

The scribes for the interconnections, back and front contacting and isolation were arranged according to the pattern in Figure 21. Microscopic analysis of the sample was made with an optical measuring microscope prior to every scribing process step in order to evaluate the scribing error margin. This was important mostly because we had to remove the sample and recalibrate the scanner head between individual process steps. The major difference in system calibration occurred between the P1 scribe and the following scribes P2 and P3 because for the first scribe a different scanner head and focusing optics was used (see Table 2). Another systematic difference was observed between the scanner and the linear motion system. The latter produces errors in the absolute position of the lines but the lines themselves are straight while the scanner head rather produces slight barrel or pillow-shaped distortions. Most of the analyzed scribes were within a $\pm 30 \mu \mathrm{m}$ error range around the planned scribe position. Based on these results we chose the following scribe-toscribe distances: $150 \mu \mathrm{m}$ between scribes was used on the "save sample" for checking the system and alignment. On the nanosecond module and on one picosecond module we used $100 \mu \mathrm{m}$ scribe-to-scribe distance and $70 \mu \mathrm{m}$ for the last sample to check out the possibilities for dead-zone reduction. 

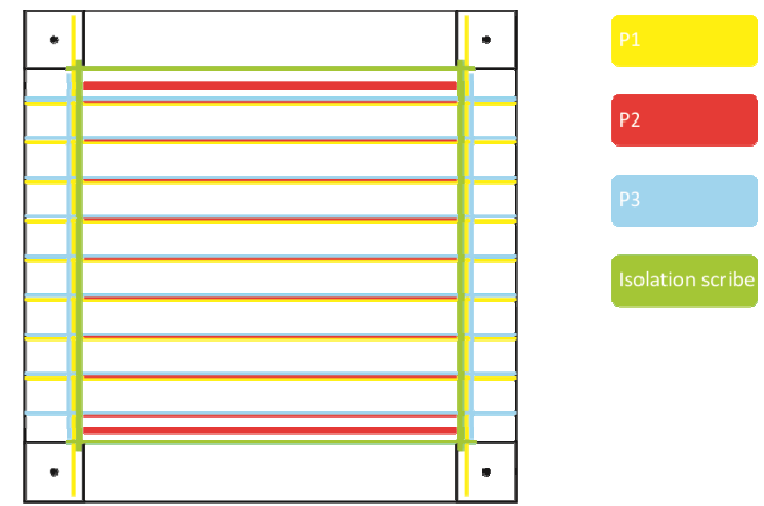

Figure 21 Scribe pattern for functional mini modules. The module consists of 8 cells with an active area of $40 \mathrm{x} 40$ $\mathrm{mm}^{2}$. The substrate dimensions are $50 \times 50 \mathrm{~mm}^{2}$. The marks in the corners are used for fine re-positioning of the sample between process steps.

\subsection{Microscopic analysis}

The functional mini-modules were microscopically analyzed before and after patterning. This was done for each process step before the modules were sent to EMPA for the next coating process. A quick evaluation of the scribes was done on an optical measurement microscope and by laser scanning microscope (LSM). The measured scribe distances and positions were used for the placement of the next scribe. LSM measurements were used as a mean of quality control of the process. The most complete information on the scribing and overall quality of the scribes is contained in the electron micrographs. In the following we present a collection of the most informative images of the functional mini-modules.

The first four images Figure 22 to Figure 25 show module number 2 which was patterned entirely with picosecond pulses (parameters according to Table 2). The scribe distance was set to $150 \mu \mathrm{m}$. The quality of the three scribes is very good; the processes could be transferred to the mini-module production without any problems.

In module 3 (Figure 26 to Figure 29) parameters were the same but the scribe-to-scribe distance was reduced to $70 \mu \mathrm{m}$. A negative effect on the scribe quality was not observed. A substantial reduction of the dead zone was realized to less than $200 \mu \mathrm{m}\left(^{3}\right)$ on the entire mini-module.

Module 4 was structured using nanosecond pulsed lasers for the P1 and P3 scribe (parameters in Table 2); P2 was made with the picosecond process. The overall result was satisfactory and the processes ran reliably. The difference to the picosecond process is expressed most obviously in the $\mathrm{P} 1$ scribe where the burr at the scribe border had a considerable impact on the following deposition processes. While in module 2 the films smoothly cover the edges of the trench in the Mo, the result is considerably different for the nanosecond module - compare Figure 23 and Figure 27 to Figure 31 and Figure 32. Both scribes have similar electrical properties but the mechanical long-term stability the films grown on top of the nanosecond scribe should be investigated. The quality of the P3 scribes was surprisingly good on module 4 and really got close to the level of the picosecond process. This process could be an interesting alternative to picosecond processes if for the specific sample the slightly bigger amount of molten CIGS has no negative effect on the electrical isolation.

Energy dispersive X-ray (EDX) spectroscopy was used during process development and on the functional samples in order to check the success of the scribing process. One example of an EDX line profile across the entire interconnection made after the P3 step is depicted in Figure 34. It shows the typical fingerprint of the elements expected in the scribing zone.

\footnotetext{
${ }^{3}$ dead zone measured from the outer border of P1 to the outer border of P3
} 
Module 2 - all picosecond

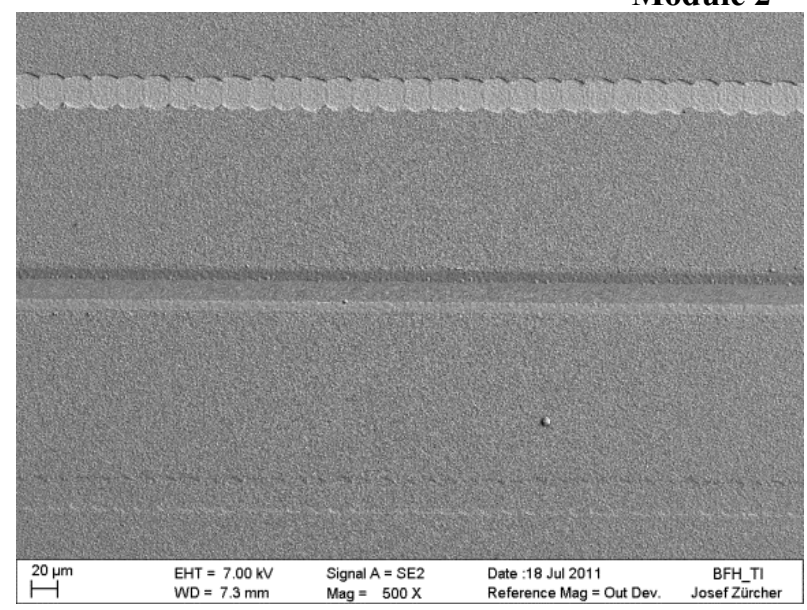

Figure 22 Module 2 (overview), scribe distance $150 \mu \mathrm{m}$

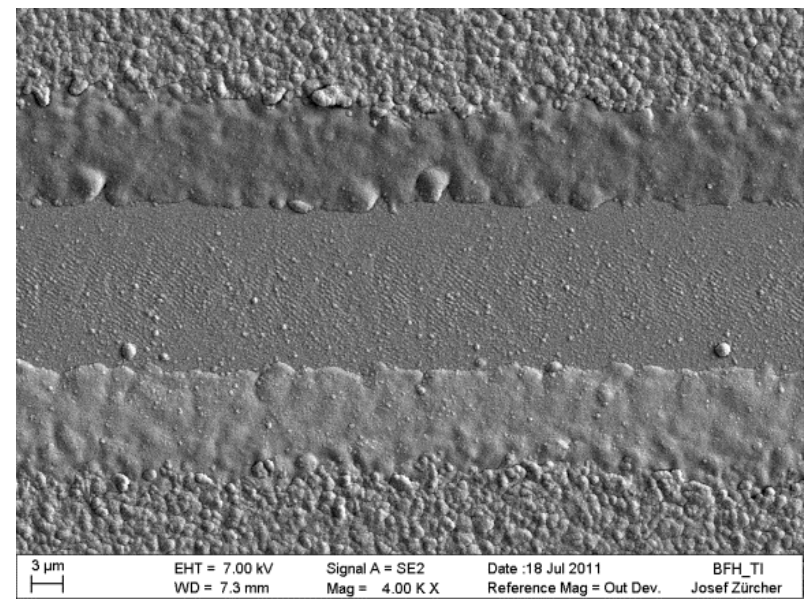

Figure 24 Module 2, P2 scribe on completed module

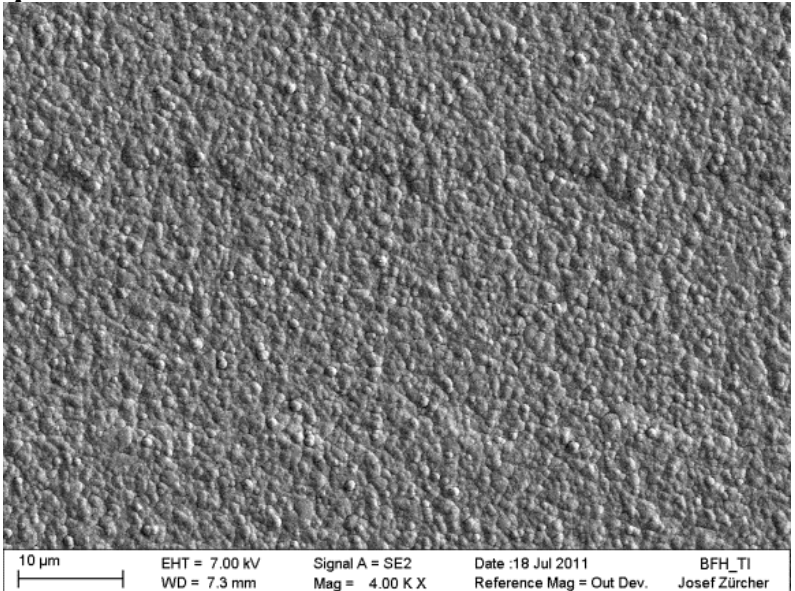

Figure 23 Module 2, P1 scribe on completed module

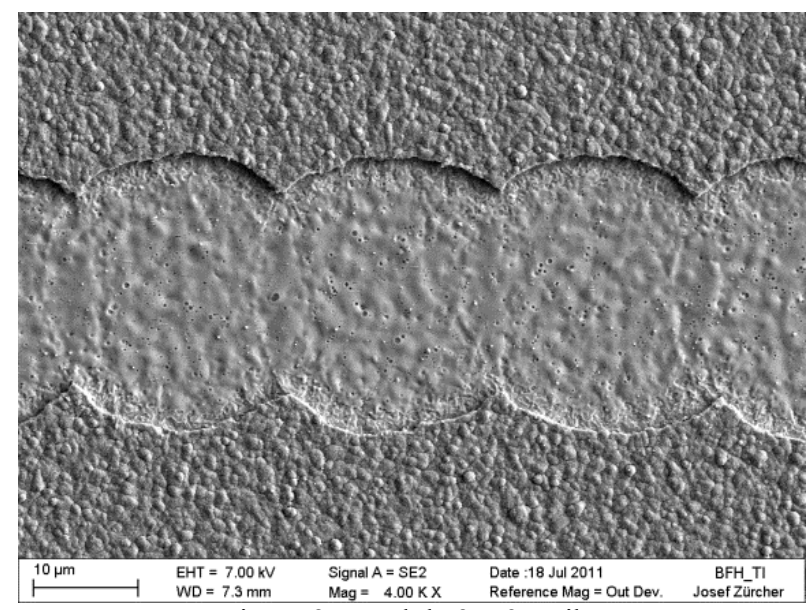

Figure 25 Module 2, P3 scribe

Module 3 - all picosecond

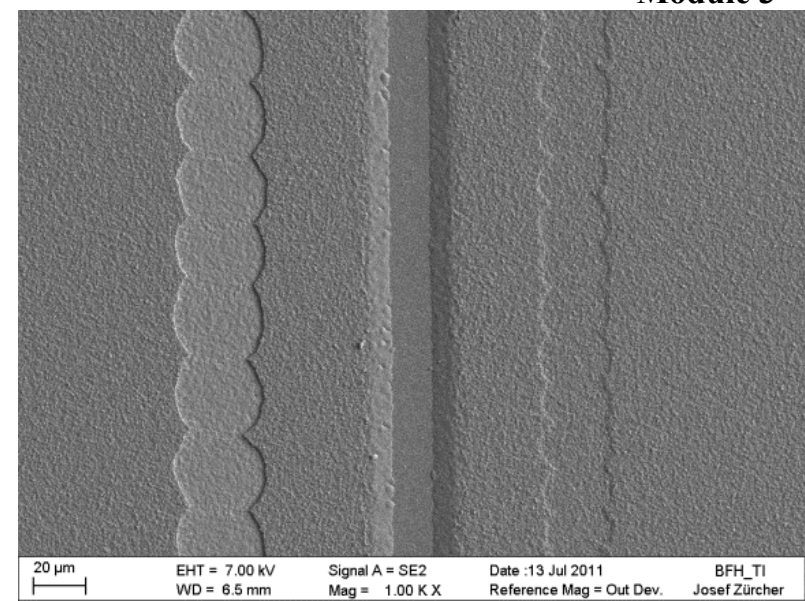

Figure 26 Module 3 (overview), scribe distance $70 \mu \mathrm{m}$

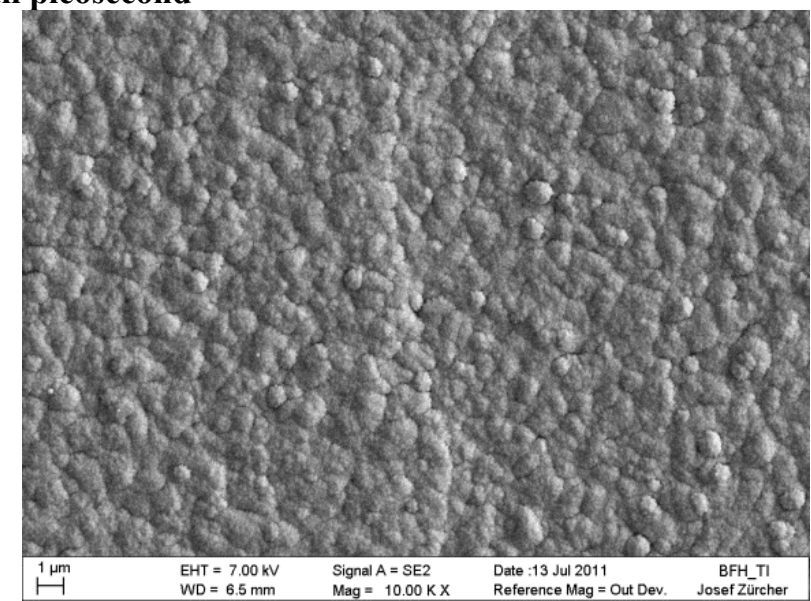

Figure 27 Module 3 (completed), P1 scribe border 


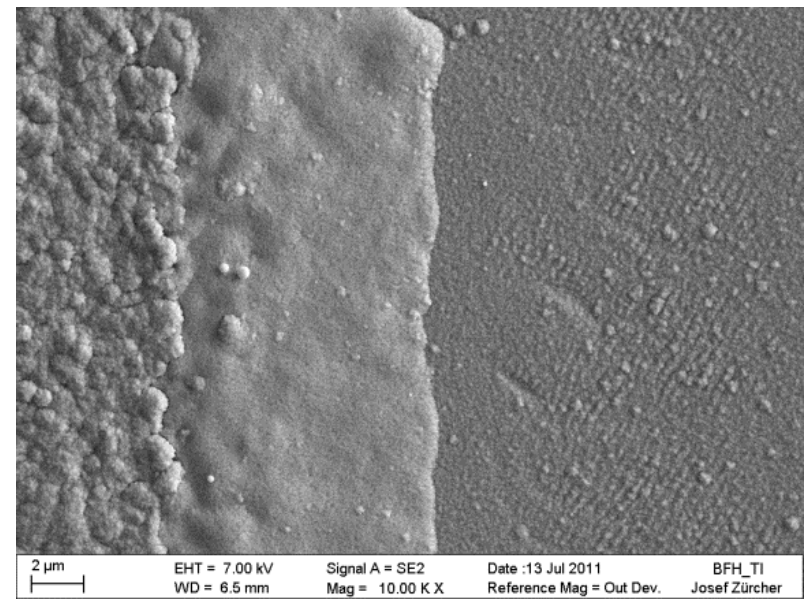

Figure 28 Module 3 (completed), P2 scribe border

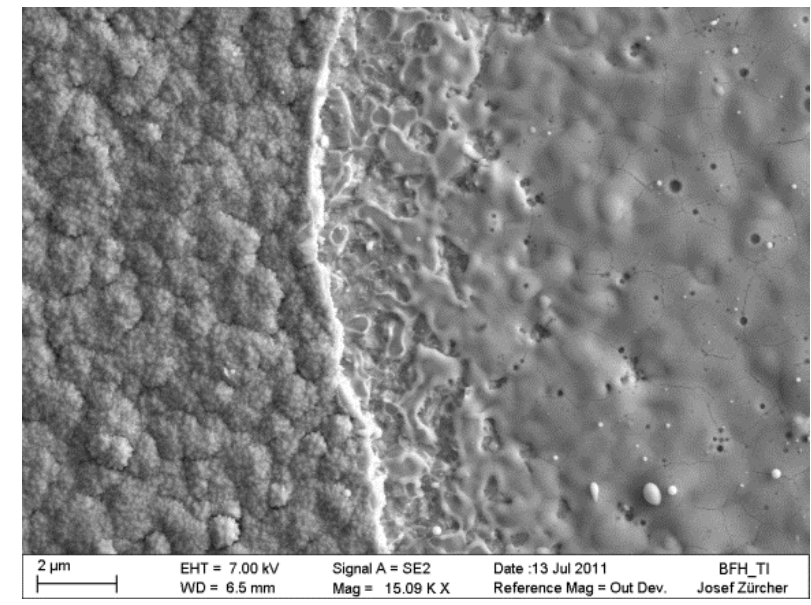

Figure 29 Module 3 (completed), P3 scribe border

Module 4 - P1 \& P3 nanosecond, P2 picosecond

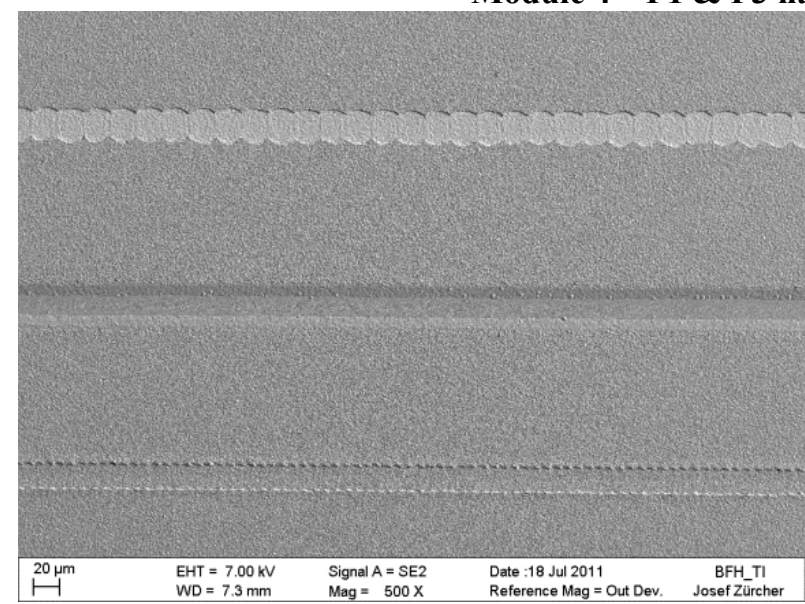

Figure 30 Module 4 (overview), scribe distance $150 \mu \mathrm{m}$

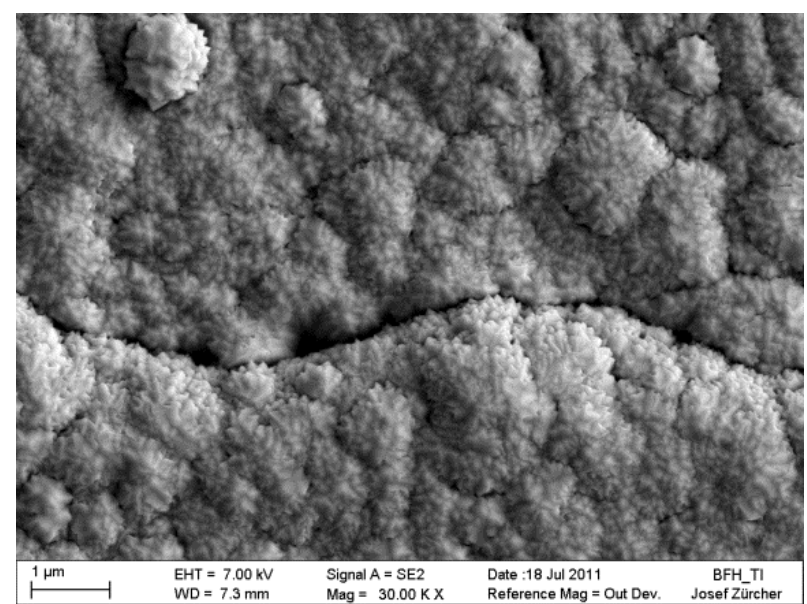

Figure 32 Module 4 (completed), P1 scribe border

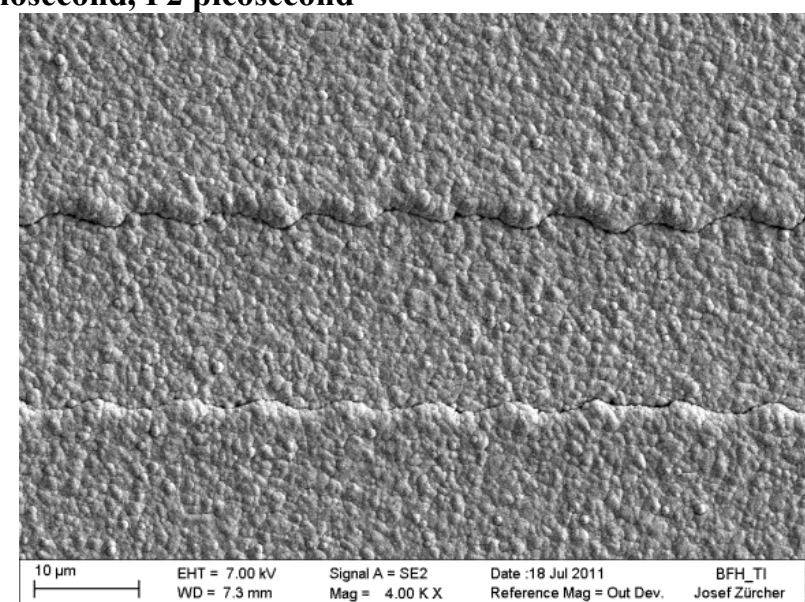

Figure 31 Module 4, P1 scribe on completed module

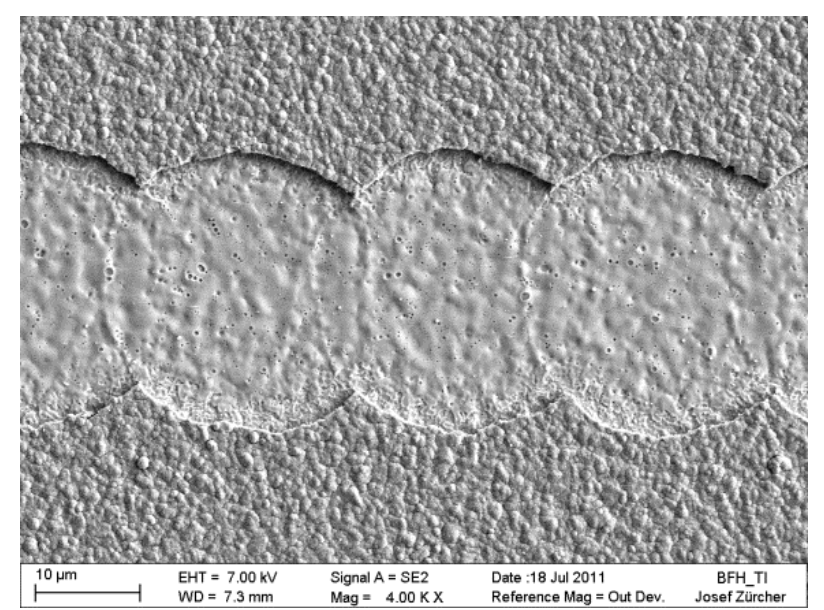

Figure 33 Module 4, P3 scribe 

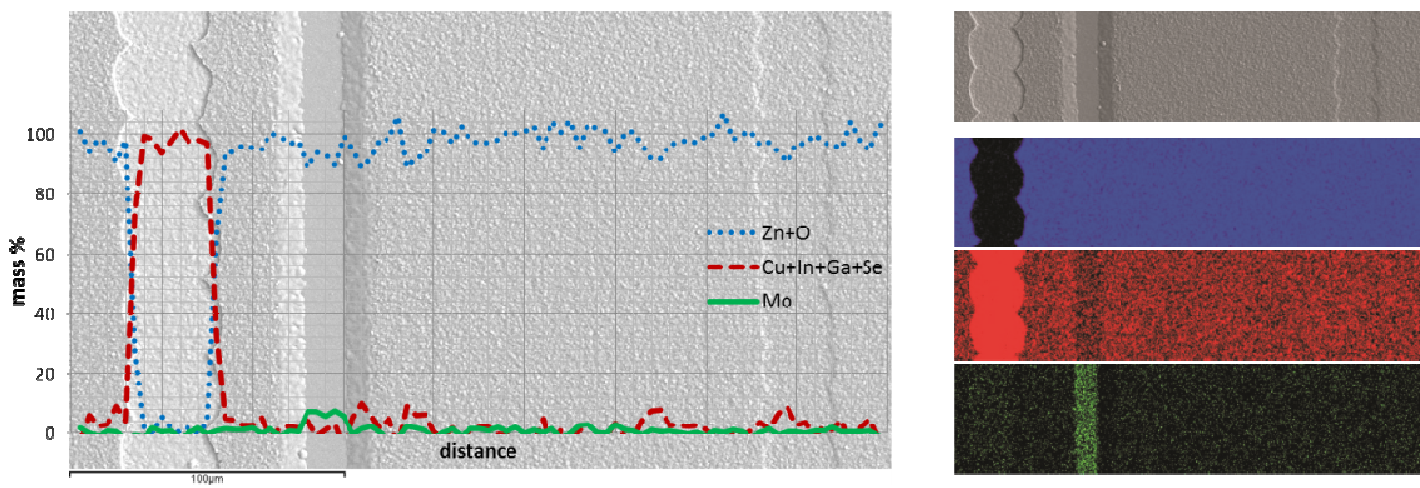

SEM

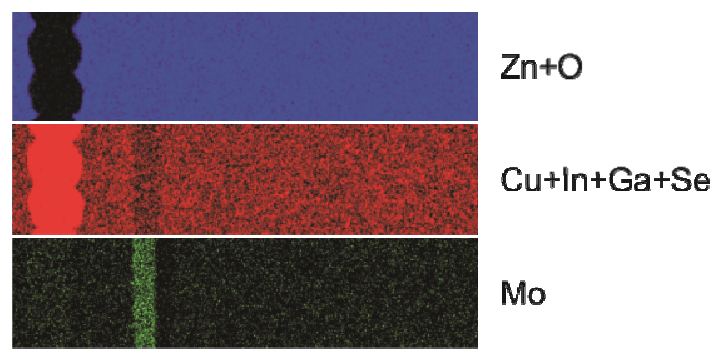

Figure 34 Left: EDX line profile across the scribe zone in module 1. The background image indicates the location of the data points on the sample. The lines in the lower part of the graphic show the relative content of the elements in mass percent. Right: EDX maps of the spatial distribution of materials in the scribing zone (sum of element counts). The SEM image of the same zone is shown for comparison.

\subsection{Electrical analysis}

The functional solar modules were analyzed by means of illuminated current voltage (JV) characteristics at the EMPA laboratory. The JV measurements were accomplished according to the international standard IEC 60904-1 under standard test conditions with AM1.5G irradiation spectrum and $1000 \mathrm{Wm}^{-2}$ irradiation intensity. The devices under test were kept at constant temperature of $25^{\circ} \mathrm{C}$ during measurement. The area of the devices was determined from a $1200 \mathrm{dpi}$ scan using graphical software. Typically, the active surface was around $12.5 \mathrm{~cm}^{2}$ per module and $1.54 \mathrm{~cm}^{2}$ per cell $(8$ cells).

The first important result was that all four modules we produced were functional. A comprehensive measure for the electrical quality of the interconnections can be obtained by comparing solar cell with solar module performance. For this purpose the module was mechanically re-scribed in order to get access to the sub cell back-contact. Figure 35 shows the functional module with exposed sub-cell back-contacts (and reduced active surface) after mechanical re-scribing.

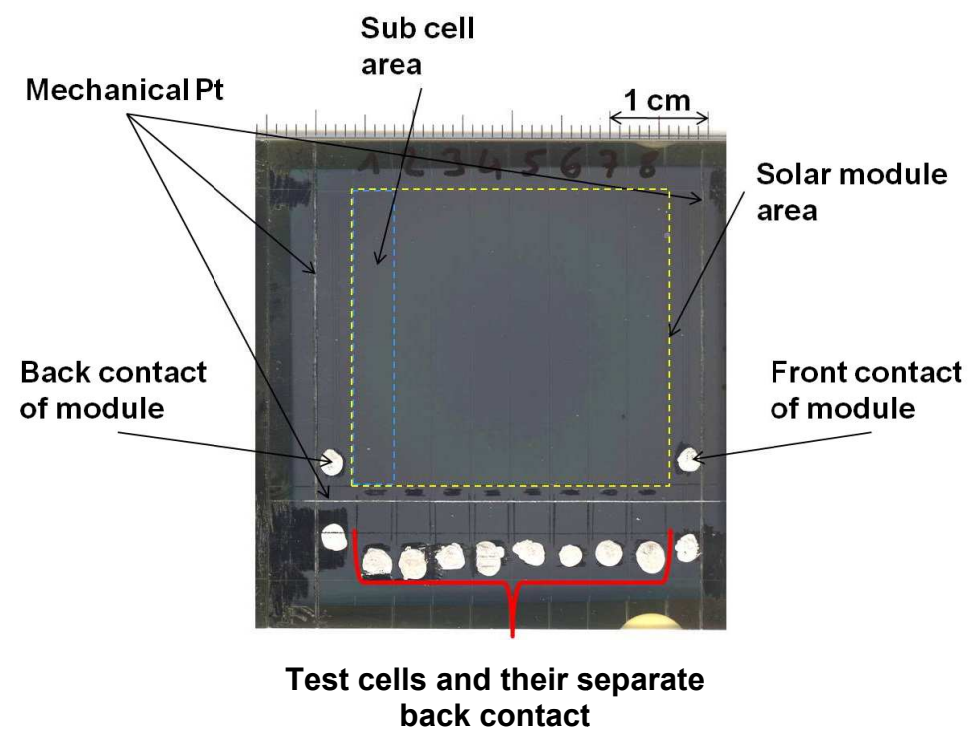

Figure 35 Scan of functional module 1 after mechanical re-scribing for sub-cell testing. 
Figure 36 compares the module performance with PV parameters of the test cells of the functional module 1. The open circuit voltage $\left(\mathrm{V}_{\mathrm{oc}}\right)$ of the module divided by the number of cells connected in series ( 8 cells) is $10 \%$ (relative) lower as measured on the test cells. Some loss is observed in the short circuit current density ( $7 \%$ relative) and in the fill factor (10\% relative) which originates from the area contact resistance losses. This leads to $16 \%$ (relative) lower efficiency of the module compared to the test cells. This evaluation would be even more favorable for module 3 where a substantially lower dead area fraction was realized due to the scribe-to-scribe distance reduction from $150 \mu \mathrm{m}$ to $70 \mu \mathrm{m}$.

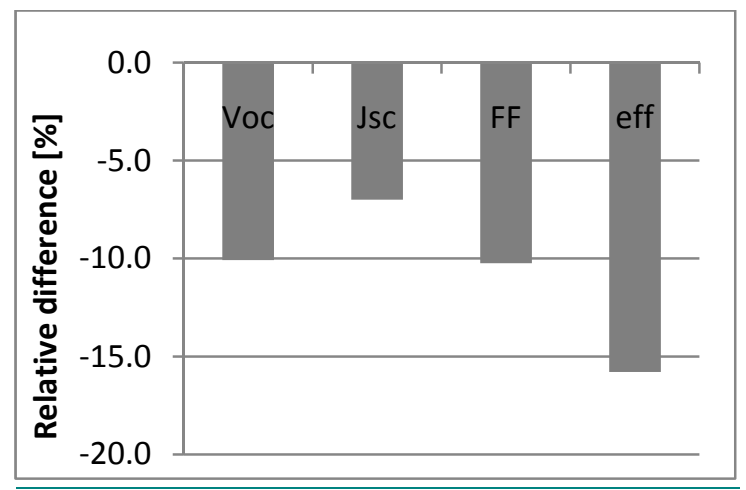

Figure 36 Graphic for module 1 showing the relative difference between module performance and performance of the sub-cells measured individually. Parameters: open circuit voltage (Voc), short circuit current density (Jsc), fill factor (FF) and overall efficiency (eff).

\section{CONCLUSIONS}

This study has shown that all-laser patterning of CIGS thin film solar modules is possible. We could develop laser based processes for all patterning steps in solar module production. Especially the picosecond pulsed laser processes did produce high quality scribes. Nanosecond laser alternative processes were found for P1 and P3. Especially for P3, the nanosecond approach could be an interesting alternative. The good scribe quality resulted in a very good electrical performance of the interconnections on the functional mini-modules. A difference of only 6 percent in the short circuit current density between 8 cell module and the sub cells underline this good result. We could show that the scribe-toscribe distance can be reduced to $70 \mu \mathrm{m}$ without any negative effect on the scribe quality. The resulting dead zone width of $<200 \mu \mathrm{m}$ was realized on an entire mini-module. All processes used for the mini-module production work at pulse durations of $30 \mathrm{ps}$ or more and at wavelengths of $532 \mathrm{~nm}$ or longer; this allows the laser to be fiber-delivered to the scribing machine. The processes were all developed on highest efficiency next generation thin film materials; therefore we can be sure that they will work also in future production lines.

\section{ACKNOWLEDGMENTS}

This study was financed in parts by the Swiss Commission for Technology and Innovation, CTI.

\section{REFERENCES}

[1] Westin, P.-O.. "By Means of Beams: Laser Patterning and Stability in CIGS Thin Film Photovoltaics," Uppsala University, 98 (2011).

[2] Seyrling, S., Chirila, A., Güttler, D., Pianezzi, F., Rossbach, P., and Tiwari, A., "Modification of the three-stage evaporation process for CuIn1-xGaxSe2 absorber deposition," Thin Solid Films 519, 7232-7236 (2011).

[3] Raciukaitis, G., Gečys, P., and Gedvilas, M., "Laser structuring of conducting films on transparent substrates for electronics devices," in Proceedings of SPIE 6732, pp. 714207-714207-15, SPIE (2008). 
[4] Gečys, P., Račiukaitis, G., Miltenis, E., Braun, A., and Ragnow, S., "Scribing of Thin-film Solar Cells with Picosecond Laser Pulses," Physics Procedia 12, 141-148 (2011) [doi:10.1016/j.phpro.2011.03.116].

[5] Compaan, A., Matulionis, I., and Nakade, S., "Laser scribing of polycrystalline thin films," Optics and Lasers in Engineering 34, 15-45, Elsevier (2000).

[6] Huber, H. P., Hellwig, C., Heise, G., Kuznicki, T., Sarrach, S., Heiss, A., Vogt, H., and Palm, J., "25th European Photovoltaic Solar Energy Conference and Exhibition / 5th World Conference on Photovoltaic Energy Conversion , 6-10 September 2010, Valencia, Spain 25th European Photovoltaic Solar Energy Conference and Exhibition / 5th World Conference on," Micro, 6-10 (2010).

[7] Witte, R., Frei, B., Schneeberger, S., Burn, A., Romano, V.,and Buecheler, S., "Optimized laser scribing of CIGS processes in substrate configuration.," in EU PV Sec Proceedings, pp. 1-6, Frankfurt (2011).

[8] Meyer, S. A., "Laser Structuring and Characterisation of Cu(In,Ga)Se2 Solar Cells.," ETH Zurich, (2007).

[9] Račiukaitis, G., "Laser Processing by Using Diffractive Optical Laser Beam Shaping Technique," Journal of Laser Micro/Nanoengineering 6, 37-43 (2011).

[10] Račiukaitis, G., "Picosecond-Laser Structuring of Thin Films for CIGS Solar Cells," Journal of Laser Micro/Nanoengineering 5, 10-15 (2010).

[11] Zoppel, S., Huber, H., and Reider, G. A.,"Selective ablation of thin Mo and TCO films with femtosecond laser pulses for structuring thin film solar cells," Applied Physics A 89, 161-163 (2007). 